\title{
Assessing Organisational Maturity in Predictive Analytics of Telecommunications Companies in the Republic of Macedonia
}

\author{
Kalina Trenevska Blagoeva $^{1}$ | Marina Mijoska ${ }^{1^{*}}$ \\ ${ }^{1}$ Ss.Cyril and Methodius University, Faculty of Economics - Skopje, Department for e-business, Republic of \\ Macedonia
}

\begin{abstract}
Data analytics and predictive analytics are among major trends companies are facing worldwide. In a highly digitalised environment, it is not only to question the usage of data analytics but how analytically mature organisations are. The goal of this paper is to assess organisational maturity in predictive analytics of telecommunications companies in the country.

In order to assess the level of organisational maturity in predictive analytics, we use Predictive Analytics Maturity Framework Assessment (PAMFA) (Capgemini, 2012), since it best describes maturity levels in the telecommunications sector. The method of analysis is based on interviewing managers with a questionnaire that guides respondents through all dimensions and levels proposed by the framework. According to the PAMFA five dimensions are analysed (Vision and strategy, Enablers, Competence, Deployment and Governance). For each dimension, four maturity levels are defined: Level 1: Impromptu, Level 2: Solo, Level 3: Ensemble and Level 4: Symphony (Capgemini, 2012).

Survey results confirmed that analysed companies fully understand the benefits of predictive analytics as a valuable source of gaining competitive advantage from data. The overall level of predictive analytics maturity is set between levels 2 or 3 for almost all dimensions.

This research is the first attempt to analyse organisational maturity in predictive analytics in the country. Its originality derives from the specific characteristics and development of the telecommunications sector. This sector is one of the most advanced service sectors in the country and hence represents a benchmark concerning digital transformation. Results of this survey provide useful information needed to design a roadmap for migrating towards higher maturity levels
\end{abstract}

Key words: organisational maturity, predictive analytics, predictive analytics maturity framework, telecommunications sector, Republic of Macedonia

JEL Classification: M19, L96

\section{INTRODUCTION}

Companies in all industries worldwide are using and benefiting from data analytics. Data analytics, especially big data analytics, advanced analytics, and predictive analytics, are among the major trends for 2017 companies worldwide are facing (Gartner, 2017). But, in spite of how powerful data analytics is, almost every organisation of every size is currently struggling with the challenges associated with building a proper analytics team and becoming a data-driven

*Corresponding author, e-mail: mijoskam@yahoo.com 
organisation. In the literature, there are a variety of explanations about what a data-driven company is and how an organisation can become one. An organisation where every individual can use data to improve decision-making and has ubiquitous access to the needed data can be considered as a data-driven company. There is no doubt that more companies will attempt to drive value and revenue from their data (Forester, 2017).

"Predictive analytics is a branch of the advanced analytics which is used to make predictions about unknown future events and uses many techniques from data mining, statistics, modelling, machine learning, and artificial intelligence to analyse current data to make predictions about future" (www.predictiveanalyticstoday.com). Predictive analytics provide analysing large amounts of data with different variables; it includes clustering, decision trees, market basket analysis, regression modelling, neural nets, genetic algorithms, text mining, hypothesis testing, and decision analytics (Mishra and Silakari, 2012). The goal is to go beyond knowing what has happened to providing a best assessment of what will happen in the future (https://www.forbes.com).

Data and analytics are also changing the nature of industry competition. The most significant changes are reported in high tech, media and telecom, and consumer and retail (McKinsey, 2016).

The ability to derive new insights from data using analytics techniques can enhance the decision-making process in companies. In today's analytics economy, in which data science is increasingly adopted by companies across all industries, it is not only to question the usage of data analytics but how analytically mature organisations are since the higher levels of analytical maturity provides better perspectives. In this sense, analytical maturity refers to organisations being able to get their business to its optimal potential by using predictive analytics. Using the maturity model can provide an understanding of the current state and help management form a strategy of what level of capability is desired in order to support the achievement of organisations objectives.

The telecommunications sector has seen momentous growth over the past decades and continues to be a critical force for growth, innovation, and disruption across multiple industries/countries. As a whole, the telecommunications industry generates upwards of 1 trillion euro in service revenues each year (https://www.statista.com/). The 54 telecommunications companies on the 2018 Forbes Global 2000 list claim more than \$3.4 trillion in assets and totalled nearly $\$ 1.5$ trillion in revenue last year (www.forbs.com). While in the past revenue was essentially sourced from a traditional landline and wireless services, today the range of products and services available in this industry is persistently increasing, offering further opportunities for revenue creation. The telecommunications industry is competing on analytics and embracing the new science of winning by investing in data science capabilities within the enterprise. These companies use predictive analytics for Analytical Customer Relationship Management (ACRM), fraud reduction, bad debt reduction, price optimisation, call center optimization, etc. In the study published by Ernst \& Young "Global telecommunications study: navigating the road to 2020", participants scored "improving big data and analytics capabilities" as very important in order to boost their organisational agility, with nearly $40 \%$ of respondents selecting it as a priority. Consumer behavior has changed significantly in the last five years. Consumers are shifting to applications like WhatsApp, Facebook Messenger, Snapchat, and Instagram rather than calling and texting. According to Stephan Gatien, General Manager of Telecommunications Business, SAP, the core services of telcos - text, voice, and data - are actually evaporating and the revenue associated with these services is evaporating as well. The big challenge in this industry is to determine how to offset the degradation of this revenue coming from text, voice, and data to a certain extent, by buying new services that will be relevant to subscribers. In the article. "Turning Data Into Insights: How Digitization Creates New Opportunities For The Telecommunications Industry, Julie Stoughton, the head of Telecommunications Marketing and Communications at SAP, stated that telecommunications 
companies are trying to reinvent themselves and stay relevant in the digital era. This has led to two major trends. First, companies are focused inward on their customer experience. They need to retain their most valuable customers and secondly, telcos are looking outward. They're considering how they can monetize the enormous volume of IoT data currently in their possession. There is no doubt that data analytics is not going to be neglected as a valuable tool for achieving that reinvention, not only for telecommunications companies but other service companies as well (Stoughton, 2018)

The telecommunications industry is area specific industry regarding predictive analytics use. This counts for the telecommunications sector in the Republic of Macedonia as well. This sector is one of the most advanced service sectors in the country and hence represent a benchmark concerning digital transformation.

In line with global trends, the telecommunications market in the country is developing rapidly, particularly in the mobile segment. Telecommunications in the Republic of Macedonia include radio, television, fixed and mobile telephones, and the Internet. According to the latest report of Agency of electronic communications of the Republic of Macedonia -AEC, the telecommunications market in the country is fully dominated by two companies (Makedonski Telekom and One. VIP) in all segments of the market (mobile, internet, fixed lines).

According to the data of the same report, in 2017,_the mobile operators' share in the mobile telephony market per number of active subscribers shows that Makedonski Telekom's share was $47.97 \%$, while One. Vip Operator's share was $49.57 \%$. The market share of mobile operators in the Republic of Macedonia by revenue generated from the provision of mobile communication services on the retail market is as follows: Makedonski Telekom has the largest market share at $52.56 \%$, while One. Vip Operator has a market share of $47.21 \%$, with a third operator having an insignificant share of $0.23 \%$. The market shares were calculated for the total revenue, which represents the sum of revenues arising from call initiation service, monthly subscription, data transfer, terminal equipment, SMS, MMS, roaming (traffic, SMS and data), and other revenues. The operators' share in the total number of active subscribers to broadband and narrowband internet access via mobile network $(2 \mathrm{G} / 3 \mathrm{G} / 4 \mathrm{G})$ states that One.VIP Operator has a market share of 52.18\%, Makedonski Telekom has a market share of $46.51 \%$, while the third operator has an insignificant market share of $1.31 \%$ (www.aek.mk).

\section{METHODOLOGY AND RESULTS}

According to the latest Data and Analytics Global Executive Study and Research Report (2018) prepared by MIT Sloan Management Review, organisations can outperform by making use of data from multiple sources. These organisations are considered innovative and analytically mature.

Data Analytics in companies matures differently with regards to different aspects/dimensions and different parts of an organisation (departments). In practice, the maturity path of an analytical organisation is not linear in all dimensions and departments. It has a more complex trajectory which is not synchronised nor by dimension or sector/department. According to Lismont (2017) "it is not unfamiliar that analytics is differently propagated throughout companies as they mature with a larger focus on department-wide or organisation-wide analytics and a more advanced data governance policy". (Lismont, 2017).

But, what analytically mature organisation means and how one organisation can become innovative and analytically mature. Different authors and consulting groups propose different analytics maturity models/frameworks in order to reach a predefined analytical maturity level. In the literature, one of the latest research representing a summary of the existing analytics maturity models is one of Chen and Nath (2018). According to their research, numerous maturity models have emerged recently, following the proliferation of the predictive analytics tools development. Chen and Nath (2018) suggest that business analytics maturity models can 
be categorized by the following determinants: technology, organization, capability, and impact focused.

One of the latest is the Analytic Processes Maturity Model (APMM) for evaluating the analytic maturity of an organisation (Grossman, 2018). The APMM identifies analytic-related processes in six key process areas, defined as: 1) building analytic models; 2) deploying analytic models; 3) managing and operating analytic infrastructure; 4) protecting analytic assets through appropriate policies and procedures; 5) operating an analytic governance structure; and 6) identifying analytic opportunities, making decisions, and allocating resources based upon an analytic strategy. Based upon the maturity of these processes, the APMM framework of Grossman (2018), organizations can differ i.e. reach five maturity levels defined as: level 1 organizations that can build reports level 2 -organizations that can build and deploy models; level 3 - organizations that have repeatable processes for building and deploying analytics; level 4 -organizations that have consistent enterprise-wide processes for analytics; and level 5 enterprises whose analytics is strategy driven. This model is based upon the Capability Maturity Model - CMM that is the basis for measuring the maturity of processes for developing software created by Software Engineering Institute, Carnegie Mellon University.

Another approach which provides estimation of analytics maturity i.e. analytical maturity levels differs organizations in three major categories based on their relative level of sophistication in adopting analytics i.e. 1) the Analytically Challenged organizations display limited analytical capabilities; 2) Analytical Practitioners largely use analytics to track and support performance indicators; and 3) Analytical Innovators incorporate analytics into virtually every aspect of their strategic decision-making, including gleaning data from a variety of sources such as direct measurement and sensors, industry data, and third parties (Ransbotham and Kiron, 2018, p.7).

According to the defined methodology, in order to determine the relative analytics proficiency of an organization, it is suggested to calculate the Analytics Core Index, based on the organization's core analytics capabilities in three major areas like: (1) ingesting data (capturing, aggregating, and integrating data); (2) analyzing data (descriptive analytics, predictive analytics, and prescriptive analytics); and (3) applying insights (disseminating data insights and incorporating insights into automated processes). In detail. the Analytics Core Index is calculated by assessing how effectively the organisation performs these seven analytics-related tasks and activities defined like 1. Capturing data, 2. Aggregating/integrating data, 3. Using descriptive analytics, 4. Using predictive analytics, 5. Using prescriptive analytics, 6. Disseminating data insights and 7. Incorporating analytics insights into automated processes (Ransbotham and Kiron, 2018, p.9). The measurement process is based on a five-point scale ranging from very ineffective to very effective. The Analytics Core Index score represents the sum of the responses to the seven questions, scaled to a range from 0 to 100 . Higher levels of analytical maturity are associated with higher levels of customer engagement, which in turn is associated with higher scores on the Analytics Core Index, which in turn is associated with greater use of diverse data sources. This means that organizations that make effective use of a wide range of data sources - from different types of technologies and different types of entities, such as customers, vendors, competitors, and publicly available sources - are more likely to use analytics to generate higher levels of customer engagement and gain a competitive advantage than organisations that use fewer sources of data. (Ransbotham and Kiron, 2018, p.9).

According to Lismont et al., (2016), the application of analytics in organisations generally differs with regards to five different aspects like: data, enterprise or organisation, leadership, targets or techniques and applications, and the analysts who apply the techniques themselves. In their research, they found that the analytics organisation in companies matures with regards to these aspects. Moreover, analytics is differently propagated throughout companies as they mature with a larger focus on department-wide or organisation-wide analytics and a more advanced data governance policy (Lismont et al., 2016). 
In our survey in order to assess the level of organisational maturity in predictive analytics, we use the Predictive Analytics Maturity Framework Assessment (PAMFA) (Capgemini, 2012), since it best describes maturity levels in the telecommunications sector. The method of analysis is based on interviewing managers with a questionnaire that guides respondents through all dimensions and levels proposed by the framework. In different business units within the same organisation, there are different maturity levels. For that reason, managers from different organisational sectors were approached and interviewed. According to the PAMFA five dimensions are analysed (Vision and strategy, Enablers, Competency, Deployment and Governance). For each dimension, managers were asked to choose the appropriate level of usage out of four available maturity levels: Level 1: Impromptu, Level 2: Solo, Level 3: Ensemble and Level 4: Symphony. This framework can serve as a roadmap for moving the organisation towards achieving its predictive analytics goals. The suggested framework which defines analytics adoption level of an organisation and its environment is illustrated in Figure 1.
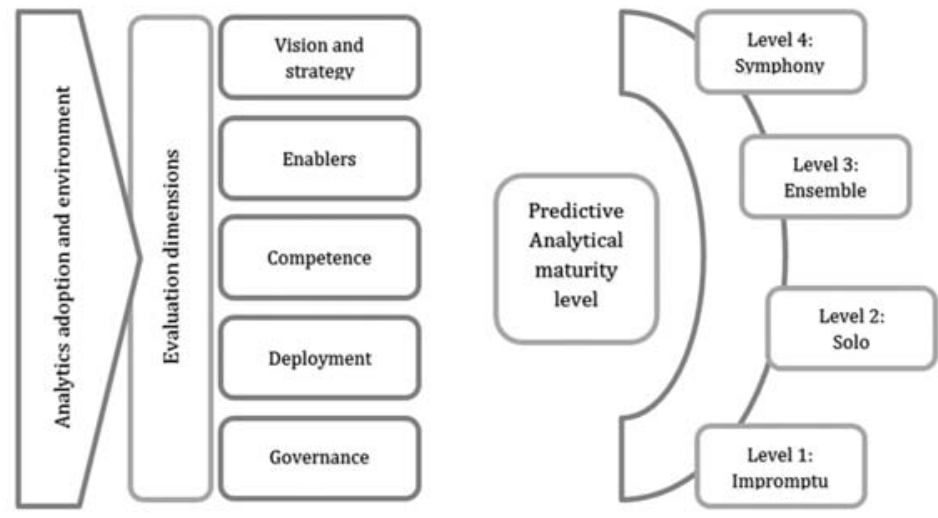

Figure 1. The PAMFA - dimensions and maturity levels

Source: Capgemini. 2012. "Measuring Organisational Maturity in Predictive Analytics: the First Step to Enabling the Vision", p.8.

According to the defined methodology, the five different aspects/dimensions of predictive analytics maturity are assessed. The first dimension is Vision and strategy. It is rare today for an organisation to develop software and information systems, without striving to use the data in best way. In this sense, having an analytics vision and strategy is very important, as the long term decisions an organisation makes about how it uses its data is needed. By defining maturity level of this dimension, the companies can write a broad "analytical map" in which the current level of the organisation will be stated, accompanied with the vision of the future wanted level. The roadmap can help in harmonising predictive analytics incentives with the organisation's high-level strategic goals.

It demonstrates where legitimisation, or execution of extra activities, is required. PAMFA looks at the current predictive analytics strategy, distinguishing any gaps and key enablers required for execution. Having a vigorous methodology set up makes it conceivable to prioritise analytics initiatives based on enterprise level business imperatives, not departmental ones.

The second measurement is called - Enablers, and it alludes to discovering how prepared the company's environment is to adopt or pursue predictive analytics. PAMFA examines the data condition, legacy solutions, analytics process, and technology and support arrangements. It likewise survey the association's comprehension of predictive analytics and its impression of the advantages. Among the empowering enablers considered in the framework are an information framework that suits predictive analytics needs and a justified portfolio of applications. 
The third dimension is Competence. This implies that organisations ought to have a full understanding of all current predictive analytics projects, and of parts where analytics could be used further on.

Next is Deployment. This measurement estimates the organisations capacity to convey predictive analytics and coordinate it into business processes which is a basic part of predictive analytics maturity. The central matter predictive analytics is to power is the decision making capability of the organisation.

The last, fifth dimension in the PAMFA is Governance. Governance is a regularly disregarded yet fundamental part of predictive analytics. Therefore, it is essential to look at the organisation's modelling lifecycle management and its administration of model precision and pertinence.

For every one of these measurements, four maturity levels are characterized. Level 1 is called Impromptu. At this level, sporadic and secluded analytic capability results from impromptu undertakings done by a solitary administrator or speciality unit. The second dimension is named Solo. Level 2 is separated into two sub-levels: Amateur Solo, implying that predictive analytics abilities and procedures exist for the most part at an individual dimension, and are not natural to the organisation, and Professional Solo which is a brilliance inside a silo. Predictive analytics processes, capacities and environment meet up to address business issues adequately, yet just for individual tasks. Level 3 is named Ensemble. On this level, one can perceive predictive analytics activities crosswise over business functionalities, with certain procedures being made together. The last, most developed level is Symphony level, where well-organised, company's wide activities apply analytics for achieving business advantage.

This framework can fill in as a guide for moving the organisation towards accomplishing its predictive analytics objectives. PAMFA is structured not exclusively to distinguish the present dimension of predictive analytics development, yet additionally to find the company's Ideal Analytics Maturity Level (IAML). The IAML is the dimension that would empower the firm both to capitalise on existing assets and furthermore to put ideally in extra assets, so as to accomplish key objectives and infer greatest business benefits.

The results of the survey confirm that analysed companies fall somewhere around level 2 or 3 for almost all dimensions. More precise, results for each dimension are shown in the table below.

Table 1: Survey results

\begin{tabular}{|l|c|c|c|c|c|c|c|c|c|c|}
\hline & \multicolumn{2}{|c|}{$\begin{array}{c}\text { Vision and } \\
\text { strategy }\end{array}$} & \multicolumn{2}{c|}{ Enablers } & \multicolumn{2}{c|}{ Competency } & \multicolumn{2}{c|}{ Deployment } & \multicolumn{2}{c|}{ Governance } \\
\hline & A & B & A & B & A & B & A & B & A & B \\
\hline Level 1 Impromptu & & & & & & & & & & \\
\hline Level 2 Solo & & & $*$ & $*$ & $*$ & $*$ & $*$ & & & \\
\hline Level 3 Ensemble & $*$ & $*$ & & & & & & $*$ & $*$ & $*$ \\
\hline Level 4 Symphony & & & & & & & & & & \\
\hline
\end{tabular}

Regarding the first dimension, vision and strategy, analysed companies are on level 3 (Ensemble). This score implies that they know about the capability of PA, yet they have not formulated enterprise vision and strategy for using predictive analytics as a valuable asset for the company as a whole. Although some employees in separate departments have an analytics vision, yet there is no single formulated analytics strategy, even for that department. The achieved level is relatively high and can be a boost for achieving higher level on other dimensions.

The maturity of the analysed companies for the second dimension - enablers is on level 2 (Solo). This implies that separate business departments may work together with innovation or business intelligence units, yet there is almost no data exchange. While discussing this 
dimension with the managers-respondents, it was obvious that they are not satisfied with the alignment of the processes.

The third dimension is called competency. Analysed companies in our research are on level 2 of maturity. This implies that some business units, individual competency may exist, but it is not used widely on a regular basis. The reported level is in correlation with the reported level of the dimension enablers, and the silo thinking is still an obstacle in this companies for performing predictive analytics and monetizing its results.

For the fourth dimension - deployment, the answers from the interview are more dispersed. This means that company A is on the second level of maturity and company B on the third. Level 2 (Solo) means that in company A integration with the business information systems is manual. For company B which is on level 3 (Ensemble), this score shows that the analytics is integrated with decision-making systems. For both companies, the predictive analytics model output is not yet integrated with business intelligence systems, decision-making systems and business information systems.

The last dimension (governance) for both companies shows level 3 of maturity. This level, Ensemble, means that business unit level governance in both companies exist but, there is still a limited enterprise-level governance.

According to the results, the overall level of predictive analytics maturity is set between levels 2 and 3 for analysed companies. Although both companies are doing well on maturity journey, there is an evident difference in the maturity of the fourth dimension - deployment.

The PAMFA can serve as a plan for guiding the organisation to achieving its predictive analytics objectives. This framework is designed not only to identify the current level of analytical maturity but also to discover the organisation's Ideal Analytics Maturity Level (IAML) (Capgemini, 2012).

The limitation of the research methodology is the subjectivity that is expected in assigning the levels by the managers-respondents. Overestimating the levels of maturity is possible. However, this bias is present in every methodology of this type.

With respect to initially measurement, vision and methodology, broke down organizations are on level 3 (Ensemble). This score implies that they know about the capability of PA, yet they have not characterised and verbalised a venture vision and technique for utilizing it on a big business level. Increasingly exact, an investigation people in some speciality units have an examination vision, yet there is no enunciated examination methodology, notwithstanding for a solitary speciality unit yet. Vision is explained by individual speciality units, alongside the IT, who need to help the vision. The accomplished dimension is moderately high and can be a lift for accomplishing a more elevated amount on different measurements.

\section{CONCLUSION}

Organisations nowadays are focused on predictive analytics as a valuable tool to use data for achieving competitive advantage. The telecommunications sector in the country is one of the most advanced service sectors and hence represent a benchmark concerning the digital transformation. The results of our survey confirmed that telecommunications companies in the country understand the benefits of predictive analytics as a valuable source to gain a competitive advantage from data. The interview results confirm that organisations fall somewhere around level 2 or 3 for almost all dimensions. This survey results provide useful information needed to design a plan for migrating towards the higher levels of maturity. The road to achieve higher levels across all dimensions is hard, and it will take full management commitment in order to maintain competitive. This research is the first attempt to analyse organisational maturity in using predictive analytics in the country. Its originality derives from

the specific characteristics and development of telecommunications sector in the country and its importance. Knowing where an organization is on this journey will help managers/strategists to 
adopt Ideal analytics maturity level, i.e. the highest level that would enable organisations to derive maximum business benefits and achieve its strategic objectives. Further research can include companies from other industries in the country (finance, health) since the PAMFA can be used to measure and describe their predictive analytics efforts.

\section{REFERENCES}

Agency for Electronic Communications of the Republic of Macedonia. 2018. "Report on the development of the electronic communications market in the Republic of Macedonia for 2017." https://www.aek.mk

Capgemini. (2012). „Measuring Organizational Maturity in Predictive Analytics: the First Step to Enabling the Vision." https://www.capgemini.com

Ernst \& Young. (2015). "Global telecommunications study: navigating the road to 2020." https://www.ey.com

Grossman, Robert L. (2018). "A framework for evaluating the analytic maturity of an organization." International Journal of Information Management, 38: 45-51

Chen, L. \& Nath, R. (2018). "Business analytics maturity of firms: an examination of the relationships between managerial perception of IT, business analytics maturity and success", Information Systems Management,. 35(1): 62-77

Lismont, J., et al. (2017). "Defining analytics maturity indicators: A survey approach." International Journal of Information Management, 37 (3): 114-124

McKinsey Global Institute. (2016). "The Age of Analytics: Competing in a Data-Driven World.“ https://www.mckinsey.com

Mishra, N. \& Silakari, S. (2012). "Predictive Analytics: A Survey, Trends, Applications, Opportunities \& Challenges." International Journal of Computer Science and Information Technologies, 3 (3): 4434- 4438

Morabito, V. (2015). "Big Data and Analytics: Strategic and Organizational Impacts." Springer

Ransbotham, S. \& Kiro, D. (2018). "Using Analytics to Improve Customer Engagement, Findings from the 2018 Data \& Analytics Global Executive Study and Research Report." MIT Sloan Management Review, https://www.sloanrieview.mit.edu

Stoughton, J. (2018). "Turning Data Into Insights: How Digitization Creates New Opportunities For The Telecommunications Industry." https://www.digitalistmag.com

Trenevska Blagoeva, K., Josimovski, S., Mijoska, M. \& Jovevski, D. (2018). "Determinants of analytics usage to improve customer engagement in chosen Macedonian companies." Knowledge - International Journal, 22(1): 187-192.

Valdez-de-Leon, 0. (2016). "A Digital Maturity Model for Telecommunications Service Providers", Technology Innovation Management Review, 6 (8): 19-32

https://www.digitalistmag.com.

https://www.forbs.com

https://www.gartner.com

https://www.infoworld.com

https://www.predictiveanalyticstoday.com

https://www.statista.com

\begin{tabular}{l|l} 
Article history: & Received: May 16, 2019
\end{tabular}

Accepted: June 21, 2019 